\title{
Critical Success Factors for \\ Integrated Library System \\ Implementation in Academic \\ Libraries: A Qualitative Study
}

\section{Shea-Tinn Yeh and Zhiping Walter}

\begin{abstract}
Integrated library systems (ILSS) support the entire business operations of an academic library from acquiring and processing library resources to making them available to user communities and preserving them for future use. As libraries' needs evolve, there is a pressing demand for libraries to migrate from one generation of ILS to the next. This complex migration process often requires significant financial and personnel investment, but its success is by no means guaranteed. We draw on enterprise resource planning and critical success factors (CSFs) literature to identify the most salient CSFs for ILS migration success through a qualitative study with four cases. We found that careful selection process, top management involvement, vendor support, project team competence, staff user involvement, interdepartmental communication, data analysis and conversion, project management and project tracking, staff user education and training, and managing staff user emotions are the most salient CSFs that determine the success of a migration project.
\end{abstract}

\section{INTRODUCTION}

The first generation of integrated library systems (ILSs) were developed specifically for library operations focused on the selection, acquisition, cataloging, and circulation of print collections. As libraries' nonprint materials steadily grow, the print-centric ILSs became less and less efficient in supporting libraries' daily operations. Recent years have seen an emergence of a new generation of ILSs, commonly called Library Services Platforms (LSPs), that takes into account the management of both print and electronic collections. LSPs take advantage of cloud computing and network advancements to provide economies of scale and to allow a library to better share data with other libraries. Furthermore, LSPs unify the entire suite of library operations to provide efficient workflow at the back end and advanced online discovery tools at the front end for the library. ${ }^{1}$ Given the claimed benefits of the emerging LSP and the fact that vendors are phasing out support for their legacy ILSs, we project that more libraries will be migrating to LSPs as the systems mature and libraries' needs evolve.

Shea-Tinn Yeh ( $\underline{\text { sheila.yeh@du.edu) }}$ is Assistant Professor and Library Digital Infrastructure and Technology Coordinator, University of Denver Libraries. Zhiping Walter (zhiping.walter@ucdenver.edu) is Associate Professor, Business School, University of Colorado Denver. 
Migrating from one generation of ILS to another is a significant initiative that affects the entire library operation. ${ }^{2}$ Because of its scale and complexity, the migration project is not always smooth and often fraught with problems, with some projects falling behind migration completion schedule.3, 4, 5 In addition, committing to a new system often results in significant financial and personnel costs for an academic library. ${ }^{6}$ Understandably, there is considerable trepidation before, during, and after the migration process. ${ }^{6,7}$ What contributes to a smooth migration process and a successful migration project? This is an urgent question at present and an enduring question for the future. This is because, as libraries continue to evolve, their operations and management needs are destined to outgrow functionalities of the current generation of ILS. Therefore migration to a new generation of ILS is destined to occur periodically for a library.

In this research, we study critical success factors (CSFs) that contribute to a smooth migration process and a successful migration project defined as on-time and on-budget project completion and a smooth implementation process. To achieve our research goal, we anchor our theoretical foundation in the enterprise resource planning (ERP) system-implementation literature. ERP is "business process management software that allows an organization to use a system of integrated applications to manage the business and automate many back office functions related to technology, services and human resources." ${ }^{9}$ Since a complete ILS is formed from a suite of integrated functions to manage a broad range of library processes, it is in fact an ERP for libraries. ${ }^{10}$ A literature review of CSFs for ERP system implementation success revealed more than ninety CSF factors. ${ }^{11,12}$ The contribution of our research is in identifying, through qualitative research method, the most salient CSFs that contribute to the success of a library system migration project from one generation of ILS to another. Results of this study can help library administrators to improve the chance of success and decrease the level of anxiety during a migration project now and in the future.

The remainder of the article is organized as follows: Section 2 reviews ERP, ILS, LSP, CSFs, and information system success measurement described in the literature. Section 3 describes the guided interviews that have been conducted to identify the CSFs, the results, and the analysis of the results. Finally, we offer conclusions and limitations as well as recommend future work.

\section{LITERATURE REVIEW}

ERP is business-management software comprising a suite of integrated applications that an organization can use to collect, store, manage, and interpret data from many business activities, including product planning, manufacturing, service delivery, marketing and sales, and human resources. The core idea of an ERP system is to integrate both the data and the process dimensions in a business so that transactions can be monitored and analyzed for planning and strategic purposes. ${ }^{13}$ Modules of the system cover different functions within a company and are linked so users can see what is happening in all areas of the company. An ERP system can improve a business's back offices as well as its front-end functions, with both operational and strategic benefits. ${ }^{14}$ Some of the benefits include reliability in information access, data and operations 
redundancy, data retrieval and reporting efficiency, easy module extension, and Internet commerce capability.

Just like an ERP system for a business, a complete library management solution comprises a suite of integrated applications that manage a broad range of library processes including circulation, acquisition, cataloging, electronic resources management, and system administration. LSPs, the current generation of library management systems, are designed to manage both physical and digital collections. LSPs follow the service-oriented architecture (SOA) and can be deployed through multitenant Software as a Service (SaaS) distribution model. ${ }^{15}$ In addition to supporting all library functions, LSPs integrate with other university systems, such as student registry and finance, and provide front-end for library patrons in a cloud environment that leverages a global network of systems for discovery of a wide array of resources. ${ }^{16}$ Since an LSP is essentially an enterprise system for library functions, CSFs of ERP implementation success could guide LSP implementation.

CSFs are conditions that must be met for an implementation to be successful. ${ }^{17}$ More than ninety CSFs have been identified for ERP implementation success. ${ }^{18,19}$ Those CSFs have been classified according to various schemes, but we found the strategic versus tactical classification most relevant to the library context. ${ }^{20}$ Strategic factors address the big picture involving the breakdown of goals into do-able items. Tactical factors, on the other hand, are the methods to accomplish the doable items that lead to achieving the goals. ${ }^{21}$ By examining the entire list of CSFs from both the strategic and the tactical perspectives, we identify top CSFs for library-management-solution implementation and migration success, defined as on-time and on-budget delivery as well as smooth implementation process, ${ }^{22,23}$ through a qualitative study.

\section{METHOD}

We conducted semi-structured interviews with open-ended questions to identify the most salient CSFs for implementation success. Since we needed to reduce more than ninety CSFs in the literature to a list of most salient CSFs in the library context and to potentially identify new CSFs, a qualitative-interview approach was more suitable than a quantitative-survey approach. A twostep process was used to arrive at the final list. First, we evaluated all CSFs in the literature and identified a subset of CSFs that might be most relevant for library-systems implementation. ${ }^{24}$ Second, this CSFs subset was used to develop an interview guide for semistructured interviews conducted later to further reduce this subset. Open-ended questions were also used during the interviews to elicit additional CSFs. An institutional review board (IRB) application was submitted and approved. The result of this two-step process is a list of ten CSFs discussed in the results section, with nine CSFs coming from our initial list and one CSF emerging from the interviews.

The criterion for recruiting study libraries is that the library has implemented a new LSP within the last three years. This is because the LSP is the current generation of ILS, and it is only within the last few years that various LSP vendors began to promote and implement the LSPs. A 
recruitment email was sent to libraries listed as adopters on various vendors' press release sites. Participating recipients referred the interview request to appropriate migration team members whom we later contacted to schedule interviews. This resulted in up to five people from each participating library being interviewed in person or via Skype. Their positions are listed in table 1. Interviews were recorded, transcribed, and cleaned. Emails to the same interviewees were used for follow-up questions as needed. After interviews with each library, qualitative data analysis was performed to identify CSFs that emerged from the interviews. Interviews continued until no new CSFs emerged in the last interview. In total, staff from four libraries were interviewed between October 2014 and March 2015 about their implementation process and experience from staff user perspective. The design and implementation of discovery public interface experience was not part of this inquiry. Table 1 summarizes characteristics of the four libraries. Case numbers instead of university names are used to protect identities of participating libraries and interviewees.

\begin{tabular}{|c|c|c|c|c|}
\hline & Case 1 & Case 2 & Case 3 & Case 4 \\
\hline Type of university & Private & Public & Public & Private \\
\hline Student population & $11,000+$ & $32,000+$ & $2,400+$ & $2,700+$ \\
\hline Operating budget & 11 million & 13 million & 1.5 million & 1.3 million \\
\hline Library employees & 150 & 400 & 17 & 13.5 \\
\hline Project length & 6 months & 9 months & 6 months & 9 months \\
\hline ILS used before & Millennium & Aleph & Evergreen & Voyager \\
\hline LSP implemented & Sierra & Alma & Sierra & Sierra \\
\hline Reasons for migration & $\begin{array}{l}\text { Discontinued } \\
\text { vendor system } \\
\text { support; servers } \\
\text { out of warranty; } \\
\text { vendor gave } \\
\text { incentives }\end{array}$ & $\begin{array}{l}\text { Outdated } \\
\text { servers; } \\
\text { servers out of } \\
\text { warranty }\end{array}$ & $\begin{array}{l}\text { In need of a } \\
\text { robust system } \\
\text { and provides } \\
\text { discovery } \\
\text { layer }\end{array}$ & $\begin{array}{l}\text { In need of a } \\
\text { modern system } \\
\text { demonstrating } \\
\text { the library's } \\
\text { moving with the } \\
\text { times }\end{array}$ \\
\hline $\begin{array}{l}\text { Positions of } \\
\text { interviewees }\end{array}$ & $\begin{array}{l}\text { Head of } \\
\text { systems; module } \\
\text { experts }\end{array}$ & $\begin{array}{l}\text { Heads of } \\
\text { systems }\end{array}$ & $\begin{array}{l}\text { Director of } \\
\text { library; head } \\
\text { of systems }\end{array}$ & $\begin{array}{l}\text { Director of } \\
\text { library }\end{array}$ \\
\hline
\end{tabular}

Table 1. Summary of case study site characteristics.

\section{RESULTS}

The following CSFs emerged from interviews: careful selection process, top management involvement, vendor support, project team competence, staff user involvement, interdepartmental communication, data analysis and conversion, project management and project tracking, staff user education and training, managing staff user emotions. We discuss each CSF next. 


\section{Careful Selection Process}

Most ILSs are commercial, off-the-shelf software systems that can vary dramatically in functionality from system to system. ${ }^{25}$ For example, some packages are more suitable for large institutions while others are more suitable for smaller ones. To mitigate risks in productivity or transaction loss and to minimize system and implementation costs, a library needs to determine the best "fitness-of-use" system. Such a determination is the outcome of a careful selection process. Although there is no commonly accepted technique, method, or tool for this process, all selection processes share common key steps suggested in the literature. ${ }^{26}$ They are the following as applied to library-systems selection: define stakeholder requirements, search for products, create a short list of most promising candidates based on a set of "must-have" requirements, evaluate the candidates on the short list, and analyze the evaluation data to make a selection. In addition, if the server option was chosen instead of the cloud option, selected hardware needs to satisfy system requirements for the final configuration.

Careful selection process emerged as a CSF that affected implementation outcome for all four libraries. All cases were migrating to an LSP system. Some systems can be offered as locally installed systems, which require appropriate in-house and hardware capabilities. Case 1 did not consider its IT capability when deciding on a turnkey system. As a result, the library experienced difficulties in setting up the infrastructure in-house during the implementation. Each of the other three cases considered the candidate system's compatibility with the legacy system, the match between library needs and system functionalities, system maturity, migration costs, data storage needs, and vendor support before and during the implementation as well as continued vendor support throughout the life of the new system. Even though each of the three libraries arrived at its system choice differently, on reflection, interviewees expressed relief and satisfaction in their decisions to choose their respective systems.

"We were in the position where our servers were out of date and warranty, needed to be replaced. The servers were too small. We had sizing issues and we couldn't update to the most recent version of Aleph ... Alma being a cloud based solution will eliminate our need to be 'in the server business.'” (Case 2).

“We went through a very extensive formal process to select this system." (Case 3)

\section{Top Management Involvement}

Successful implementation requires strong leadership by executives who understand, support, and champion the project. ${ }^{27}$ When this involvement is trickled down through organizational hierarchy, it leads to an organizational commitment, which is required for implementation success for complex projects. ${ }^{28,29}$ Since library-system implementation is a complex project that (if done correctly) will transform the entire library and reposition it for better efficiency, strong leadership is critical as well. 
In all four cases, top management were involved in the final decisions of their respective system choices. In cases 1 and 2, top management also took charge in securing funding for the migration projects. Interviewees stressed that top management support was very important in their respective project implementations.

"The top level management took the recommendations from the systems librarians at the time, with the blessing of the council determined whether they want to proceed with the product Alma, and had funding conversations with the financial people." (Case 2)

"We have faculty library committee, faculty governance oversight. We showed them webinars of the products we considered before we signed them, so we have faculty representation on board. We held open forum and were inclusive in our invitations." (Case 4)

\section{Vendor Support}

With a new technology, it is critical to acquire external technical expertise, often from the vendor, to facilitate successful implementation. ${ }^{30}$ Effective vendor support includes adequate and highquality technical support during and after implementation, sufficient training provided for both the project team and staff users, and positive relationships between all parties in the project. ${ }^{31}$ Additionally, there should be adequate knowledge transfer between the vendor consultants and the clients, which can be achieved by defining roles, achieving shared understanding, and enhancing relationships through competent communication. ${ }^{32,33}$ In the case of library-system implementations, vendor support is particularly important because of the complexity of each new generation of the system and the library personnel's knowledge gap in understanding the nuts and bolts of the new system.

Effective vendor support was identified in each case as a critical success factor determining the implementation outcome even though the form of vendor support varied from case to case. In case 1 , the vendor sent different consultants with various expertise as project managers on the basis of the project phase. In case 2 , the vendor sent one consultant who served as the main project manager. In case 3 , the vendor provided a project manager and a team of technicians. In case 4 , consultants were shared across multiple consortium libraries that were implementing the system at the same time. No matter how vendor support was provided, it was essential for implementation success as indicated by interviewees.

"The vendor has been very supportive and provides a group of experts throughout the process, some are knowledgeable in server business while others are skilled project managers." (Case 1)

\section{Project Team Competence}

Since library-system migration affects all functional areas of a library, members of the implementation team need to be cross-functional. Furthermore, members with both business 
knowledge and technology knowhow are especially crucial for implementation success. ${ }^{34}$ Competence of vendor consultants assigned to the project also influences implementation success, as discussed earlier. Additionally, it is important to have an in-house project leader who champions the project and who has the essential skills and authority to set goals that legitimize change. 35

Having a competent project team was essential for implementation success for each of our cases. In each case, the vendor provided the project manager and the library provided a co-manager who was a champion figure. Other team members came from various functional areas such as acquisition, circulation, cataloging, electronic resources management, and system administration. For example, in case 1, the technology librarian participated as a co-project manager. The projectmanagement team comprised module experts within the library and from functional areas. In addition, the university's technology services department lent technical support during early stages of implementation when servers need to be set up. The interviewees all stressed the importance of project-team competence.

"Without the infrastructure knowledge from the university's technology team and their time and full support to negotiate with the vendor, the migration project would not have been possible." (Case 1)

"The university's IT made sure that we are in compliance with campus policies and expectations for securities." (Case 2)

\section{Staff User Involvement}

It is important that the project team involve staff users early on, otherwise the implementation process may be bumpy. When end users are involved in decisions relating to system selection and implementation, they are more invested in and concerned with the success of the system, which in turn leads to greater system use and user satisfaction. ${ }^{36,37}$ As such, it is one of the most cited critical success factors in ERP implementation. ${ }^{38}$ Because personal relevance to the system is just as important for library-system implementation, effective staff user involvement with implementation is positively related to implementation success.

Staff user involvement has emerged as a main success factor in all our cases and contributed to the implementation project outcome. In case 1, staff users were not consulted as to whether an LSP was necessary for the library, although they were informed of the reasons for implementation. Additionally, staff users were not involved when the project timetable was negotiated. This lack of early staff user involvement led to considerable stress down the road, which made the implementation process bumpy. The other three cases involved staff users early on; as a result, staff users experienced much less stress and frustration down the road. Specifically, in case 2, the staff users were educated about the need for migration through staff meetings, town hall meetings, supervisory meetings, council meetings, and forums. Many product-demo sessions were conducted for the staff so they would have the knowledge to participate before the final decision 
was made. There were daily internal newsletters conveying implementation news throughout implementation months. In case 3, the entire library was involved with the selection of a new system. While the key staff (such as circulation manager, acquisition manager, and reference manager) had more input than others, everyone offered input about the project. As such, the buyin with the new system was strong from all stakeholders. In case 4, staff users were involved early on through open forums and webinars. The following quotes are examples of interviewee sentiment concerning staff user involvement:

"Everybody is involved in choosing the system; partially because Evergreen had been so problematic. We wanted to make sure that everyone is on board." (Case 3)

"Migration is the most time consuming aspect of the library staff work during the time of the project, without their buy-ins, it is difficult to have a successful project." (Case 4)

\section{Interdepartmental Communication}

The importance of effective communications across functional and departmental boundaries is well known in information-systems-implementation literature. ${ }^{39}$ With consultants coming from the vendor, project team members coming from different functional areas, and staff users with different perceptions and understandings of the implementation project, the importance of effective communications between all involved cannot be overstated. Communications should start early, be consistent and continuous throughout various stages of the implementation process, and include a system overview, rationale for implementation, briefings for process changes, and contact-points establishment. ${ }^{40}$ Expectations and goals should be communicated to all stakeholders and to all levels of the organization. ${ }^{41}$ Effectiveness of interdepartmental communication affected the implementation outcome in all our cases.

In case 1, the library's project manager was designated to communicate with the vendor when issues arose, such as hardware and software configurations, system backup and use, and task assignments. The formal project plan was established using the web-based Basecamp so that team members in different roles with different responsibilities could communicate and work together online. Regular meetings were held and emails were exchanged between project team members. However, there is a lack of effective interdepartmental communication with staff who were not on the project team. This resulted in the absence of necessary system testing that would have detected some data-integrity issues. Such issues later caused the system to be offline for days, which brought much frustration and stress to everyone. In the other three cases, all actors were well informed through news releases, meetings, presentations, and webinars. Concerns were communicated to the project team and addressed timely. As a result, the level of frustration was very low for those three cases.

\section{Data Analysis and Conversion}

A fundamental requirement for the effectiveness of an ERP system is the accuracy of its data, ${ }^{42}$ and the same is true for a library system. Data types in a legacy ILS are often of an outdated format and 
can differ from formats supported by a new library system. Conversion from one format to another can be an overwhelming process, especially when there is no existing expertise in the library. Since migrating legacy data to the new system is essential, effective data analysis for conversion is a critical success factor for implementation success.

The smoothness of each of the four implementation cases was related to the project team's data analysis and conversion efforts. In case 1, the library did not spend any effort to analyze, convert, or clean the data. As a result, the system experienced data-integrity issues after it went live. The other three libraries either devoted time to clean and convert the data or had a third party do the data cleaning. As a result, no system issues arose from data-integrity problems. Interviewees from case 2 told us, "We elected to freeze the data 30 days sooner in terms of bibliographic data, so that we can do an authority control project with a third party vendor."

\section{Project Management and Project Tracking}

According to ERP implementation literature, effective project-management practices are critical for implementation success. Such practices include defining clear objectives, establishing a formal implementation plan, designing a realistic work plan, and establishing resource requirements. ${ }^{43}$ The formal implementation plan needs to identify modules to be implemented, tasks to be undertaken, and all technical and nontechnical issues to be considered. ${ }^{44}$ Project progress must be carefully monitored through meetings and reports. ${ }^{45,46}$

Effective project management and tracking has affected implementation outcome in all our cases. A popular project management and tracking software is Basecamp, a web-based project management and collaboration tool initially released in $2004 .{ }^{47}$ It offers discussion boards, to-do lists, file sharing, milestone management, event tracking, and messaging system that help project teams stay organized and connected despite their different locations. All cases used Basecamp for project management and tracking, which contributed to on-time and on-budget project completion for all cases.

\section{Staff User Education and Training}

A new system often frustrates users who do not receive adequate training in its functionalities and use. $^{48}$ When feeling frustrated and stressed, users may avoid using the system. Proper and adequate training will sooth users and eliminate their reluctance to use the new system, which in turn helps realize productivity gains. 49,50 Training processes should consider factors such as training curriculum, user commitment, trainers' personnel skills and competence, as well as training schedule, budget, evaluation, and methods. ${ }^{51}$

Effective staff user training has emerged as a critical success factor from all our cases. In case 1, staff users had access to a vendor-supplied preview portal, which simulated system functionalities. Staff users were so familiar with the new system by the time the system went live that they were eager to engage with it. In cases 2, 3 and 4, staff users were trained through demo products, online video trainings, Q\&A, and on-site training sessions conducted by the vendor. 
These training materials and sessions served to ease staff user's feeling of uncertainty and anxiety, as the following quotes show:

"The online training videos were provided to all staff in the library and followed up with Q\&A sessions which members of the committee will host in their respective areas.... Then Ex Libris did a week long onsite training workshop serve for the final deep configuration issues.... We know that there are staff users who want to be ahead of the game, yet there are always people who don't want to learn until the day before they go live." (Case 2)

"We have a training package with several onsite visits, each one is for a few days. The trainer focused on one aspect of the system. It was more than watching the videos online. Because of the small staff here, almost everyone attended at least one training." (Case 3)

"The trainers varied with their expertise, we developed fondness for some more than others. The training is functional in nature. The vendor's priority was about trainer availability and to keep the project on time. We became familiar with trainers' expertise; we were able to request the right trainer with the job." (Case 4)

\section{Managing Staff User Emotions}

Although education and training eases user anxiety, it does not completely eliminate it. Emotions felt by users early in the implementation of a new system have important effects on the use of the system later on. ${ }^{52}$ How to manage staff user anxiety and negative emotions when they appear has emerged as a critical success factor in all our cases, as shown in the following quotes:

"There were so many things going on in the library during the migration go-live week. The unknown of the migration success made staff users uncomfortable. Should the migration date be decided in consideration of other initiatives, the frustration experienced would have been a lot less and might not have been ignored during the going-live week." (Case 1)

"The frustration was just change; it was the fact that we have to learn something new... . Primarily the frustration was handled by the lead." (Case 2)

"There was a challenge, especially early on, in getting people to engage with the manuals and the literature in documentation. It is as if everyone is being asked to learn a new language... . The key relationship between the onsite coordinator and the project manager on the vendor side is important. When those two exchange information and handle frustration diplomatically, this bridge between the two organizations can smooth over a lot of rough feathers on either or both sides." (Case 4) 
This final CSF did not come directly from the ninety-plus CSFs that we started with, although it aligned closely with "Change Management" category. ${ }^{53}$ This CSF emerged mostly from the interview process.

\section{Summary of Results}

The results of the case studies for each critical factor are summarized in table 2. Implementation project outcome is summarized in table 3. An implementation is considered successful if it was completed on-time and on-budget and if the implementation process was smooth as reflected in the number and degree of unexpected problems along the way.

\begin{tabular}{|l|l|l|l|l|}
\hline Critical Success Factor & Case $\mathbf{1}$ & Case 2 & Case 3 & Case 4 \\
\hline Careful selection process & No & Yes & Yes & Yes \\
\hline Top management involvement & Yes & Yes & Yes & Yes \\
\hline Vendor support & Yes & Yes & Yes & Yes \\
\hline Project team competence & Yes & Yes & Yes & Yes \\
\hline Staff user involvement & No & Yes & Yes & Yes \\
\hline Interdepartmental communication & No & Yes & Yes & Yes \\
\hline Data analysis \& conversion & No & Yes & Yes & Yes \\
\hline Project management and tracking & Yes & Yes & Yes & Yes \\
\hline Staff user education and training & Yes & Yes & Yes & Yes \\
\hline Managing staff user emotions & No & Yes & Yes & Yes \\
\hline
\end{tabular}

Table 2. Summary of case study critical success factors findings

\begin{tabular}{|l|l|l|l|l|}
\hline \multicolumn{2}{|c|}{ Case 1} & Case 2 & Case 3 & Case 4 \\
\hline On time implementation & Yes & Yes & Yes & Yes \\
\hline $\begin{array}{l}\text { On budget implementation } \\
\text { implementation }\end{array}$ & Yes & Yes & Yes & Yes \\
\hline & $\begin{array}{l}\text { No } \\
\text { Staff users experienced data } \\
\text { integrity issue, system } \\
\text { downtime, as well as } \\
\text { anxiety and stress with the } \\
\text { system implementation } \\
\text { process }\end{array}$ & Yes & Yes & Yes \\
\hline
\end{tabular}

Table 3. Summary of case study implementation success measures

\section{DISCUSSION AND CONCLUSIONS}

The implementation of a new ILS is a large-scale undertaking that affects every aspect of a library's operations as well as every staff user's workflow process. As such, it is imperative for 
library administrators to understand what factors contribute to a successful implementation. Our qualitative study shows that there are two categories of CSFs: strategic and tactical. From the strategic perspective, top management involvement, vendor support, staff user involvement, interdepartmental communication, and staff user emotion management are critical. From the tactical perspective, project team competence, project management and project tracking, data analysis and conversion, and staff user education and training to break down the technical barrier greatly affect implementation outcome. In addition, selection of the final system from a variety of choices and options requires a careful consideration of both strategic and tactical issues. Each factor identified is important in its own right during the implementation process. Combined, they complement each other to guide an implementation to success.

Among the list of CSFs identified, the role of staff user emotion management was not identified during the theoretical phase of the study; it only emerged as an important CSF during interviews. Top management involvement, vendor support, project team competence, project management and tracking, and staff user education and training are CSFs that were somewhat intuitive, and they were implemented by all cases. However, a library may select an end system without careful considerations. It may also be unaware of the importance of involving users early on, the importance of opening clear lines of interdepartmental communications, or the importance of performing data analysis and conversion before the implementation. Staff user emotion management, especially, is at the risk of being an afterthought of an implementation.

By identifying the most salient CSFs, this study offers practical contributions to academic library leaders and administrators in understanding how critical success factors play a role in ensuring a smooth and successful ILS implementation. Although CSFs have been extensively studied in the discipline of information-systems management, this is the first study to apply CSFs in the library context. Since library management has its unique challenges compared to businesses, identifying CSFs for library-system-implementation success is important not only for the current migration to LSPs but also for future migrations to future generations of ILSs as the needs of libraries continue to evolve.

As with any empirical research, there are limitations to this study. The number of academic libraries interviewed is small despite no new information being discovered after the fourth interview. The vendors represented in this study are only two of the many in the market providing LSPs to libraries. With these aforementioned limitations, the results of this study may not be generalizable to libraries implementing an LSP with vendors other than Innovative Interfaces and Ex Libris. Additionally, the results may not be generalizable to nonacademic libraries.

This research can be extended to validate the proposed CSFs quantitatively by performing a survey research in academic libraries. Studying interactions between identified factors will offer an even greater contribution. This research can be experimented in other types of libraries to generalize inferences. In addition, case libraries 3 and 4 both expressed that LSP changes the public interface that is used by external users, and they wished to have more opportunities for outreach prior to the implementation. Although the design and implementation of the public interface was not considered within the scope of this research, this comment is insightful because 
it may imply that future studies should consider a project champion to be a critical success factor. The project champion must have people-related skills and position to introduce changes in achieving buy-in from staff users. 54,55

\section{REFERENCES}

1. Richard M. Jost, Selecting and Implementing an Integrated Library System: The Most Important Decision You Will Ever Make (Boston: Chandos, 2015).

2. Ibid., 3 .

3. Suzanne Julich, Donna Hirst and Brian Thompson, "A Case Study of ILS Migration: Aleph500 at the University of Iowa," Library Hi Tech 21, no. 1 (2003): 44-55, http://dx.doi.org/10.1108/07378830310467391.

4. Zahiruddin Khurshid, "Migration from DOBIS LIBIS to Horizon at KFUPM," Library Hi Tech 24, no. 3 (2006): 440-51, http://dx.doi.org/10.1108/07378830610692190.

5. Vandana Singh, "Experiences of Migrating to an Open-Source Integrated Library System," Information Technology \& Libraries 32, no. 1 (2013): 36-53.

6. Jost, "Selecting and Implementing an Integrated Library System."

7. Yongming Wang and Trevor A. Dawes, "The Next Generation Integrated Library System: A Promise Fulfilled," Information Technology \& Libraries 31, no. 3 (2012): 76-84.

8. Keith Kelley, Carrie C. Leatherman, and Geraldine Rinna, "Is It Really Time to Replace Your ILS with a Next-Generation Option?” Computers in Libraries 33, no. 8 (2013): 11-15.

9. Vangie Beal, “ERP_Enterprise Resource Planning,” Webopedia, http://www.webopedia.com/TERM/E/ERP.html.

10. “Library Management System," Tangient LLC, https://libtechrfp.wikispaces.com/Library+Management+System.

11. Christopher P. Holland and Ben Light, “A Critical Success Factors Model for ERP Implementation," IEEE Software 16, no. 3 (1999): 30-36, http://dx.doi.org/10.1109/52.765784.

12. Levi Shaul and Doron Tauber, "Critical Success Factors in Enterprise Resource Planning Systems: Review of the Last Decade," ACM Computing Surveys 45 no. 4 (2013): 1-39, http://dx.doi.org/10.1145/2501654.2501669.

13. Yahia Zare Mehrjerdi, "Enterprise Resource Planning: Risk and Benefit Analysis," Business Strategy Series 11, no. 5 (2010): 308-24, http://dx.doi.org/10.1108/17515631011080722.

14. Mohammad A. Rashid, Liaquat Hossain, and Jon David Patrick, "The Evolution of ERP Systems: A Historical Perspective," in Enterprise Resource Planning: Global Opportunities and Challenges (Hershey, PA: Idea Group, 2002). 
15. Marshall Breeding, "Library Systems Report 2014: Competition and Strategic Cooperation," American Libraries 45, no. 5 (2014): 21-33.

16. Sharon Yang, "From Integrated Library Systems to Library Management Services: Time for Change?" Library Hi Tech News 30, no. 2 (2013): 1-8, http://dx.doi.org/10.1108/LHTN-022013-0006.

17. Shahin Dezdar, "Strategic and Tactical Factors for Successful ERP Projects: Insights from an Asian Country," Management Research Review 35, no. 11 (2012): 1070-87, http://dx.doi.org/10.1108/14637151111182693.

18. Ibid.

19. Shahin Dezdar and Ainin Sulaiman, "Successful Enterprise Resource Planning Implementation: Taxonomy of Critical Factors," Industrial Management \& Data Systems 109, no. 8 (2009): 103752, http://dx.doi.org/10.1108/02635570910991283.

20. Sherry Finney and Martin Corbett, "ERP Implementation: A Compilation and Analysis of Critical Success Factors," Business Process Management Journal 13, no. 3 (2007): 329-47, http://dx.doi.org/10.1108/14637150710752272.

21. F. Pearce, Business Building and Promotion: Strategic and Tactical Planning (Houston: Pearman Cooperation Alliance, 2004).

22. Jennifer Bresnahan, "Mixed Messages," CIO (May 16, 1996), 72, http://dx.doi.org/10.1016/j.jchf.2013.07.005.

23. Majed Al-Mashari, Abdullah Al-Mudimigh, and Mohamed Zairi, "Enterprise Resource Planning: A Taxonomy of Critical Factors," European Journal of Operational Research 146, no. 2 (2003): 352-64, http://dx.doi.org/10.1016/S0377-2217(02)00554-4.

24. Shaul and Tauber, "Critical Success Factors in Enterprise Resource Planning Systems."

25. H. Akkermans and K. van Helden, "Vicious and Virtuous Cycles in ERP Implementation: A Case Study of Interrelations between Critical Success Factors," European Journal of Information Systems 11, no. 1 (2002): 35-46, http://dx.doi.org/10.1057/palgrave.ejis.3000418.

26. Abdallah Mohamed, Guenther Ruhe, and Armin Eberlein, "COTS Selection: Past, Present, and Future" (paper presented at the 14th Annual IEEE International Conference and Workshops on the Engineering of Computer-based System, 2007), http://dx.doi.org/10.1109/ECBS.2007.28.

27. M. Michael Umble, Elisabeth J. Umble, and Ronald R. Haft, "Enterprise Resource Planning: Implementation Procedures and Critical Success Factors," European Journal of Operational Research 146 no. 2 (2003): 241-57, http://dx.doi.org/10.1016/S0377-2217(02)00547-7.

28. Jim Johnson, "Chaos: the Dollar Drain of IT Project Failures," Application Development Trends 2, no. 1 (1995): 41-47. 
29. Prasad Bingi, Maneesh K. Sharma, and Jayanth K. Godla, "Critical Issues Affecting an ERP Implementation," Information Systems Management 16, no. 3 (1999): 7-14, http://dx.doi.org/10.1201/1078/43197.16.3.19990601/313.

30. Mary Sumner, "Critical Success Factors in Enterprise Wide Information Management Systems Projects," Proceedings of the 1999 ACM SIGCPR Conference on Computer Personnel Research, 1999 (New York: ACM, 1999), http://dx.doi.org/10.1145/299513.299722.

31. Eric T. G. Wang et al., "The Consistency among Facilitating Factors and ERP Implementation Success: A Holistic View of Fit," Journal of Systems \& Software 81 no. 9 (2008): 1609-21, http://dx.doi.org/10.1016/j.jss.2007.11.722.

32. Dong-Gil Ko, Laurie J. Kirsch, and William R. King, "Antecedents of Knowledge Transfer from Consultants to Clients in Enterprise System Implementations," MIS Quarterly 29, no. 1 (2005): 59-85.

33. Al-Mashari, "Enterprise Resource Planning."

34. Fiona Fui-Hoon Nah and Santiago Delgado, "Critical Success Factors for Enterprise Resource Planning Implementation and Upgrade," Journal of Computer Information Systems 46 no. 5 (2006): 99-113.

35. Liang Zhang et al., "A Framework of ERP Systems Implementation Success in China: An Empirical Study," International Journal of Production Economics 98, no. 1 (2005): 56-80, http://dx.doi.org/10.1016/j.ijpe.2004.09.004.

36. Ann-Marie K. Baronas and Meryl Reis Louis, "Restoring a Sense of Control During Implementation: How User Involvement Leads to System Acceptance," MIS Quarterly 12, no. 1 (1988): 111-24.

37. Joseph Esteves, Joan Pastor and Joseph Casanovas, "A Goals/Questions/Metrics Plan for Monitoring User Involvement and Participation in ERP Implementation Projects," IE working paper, March 11, 2004, http://dx.doi.org/10.2139/ssrn.1019991.

38. Khaled Al-Fawaz, Zahran Al-Salti, and Tillal Eldabi, "Critical Success Factors in ERP Implementation: A Review" (paper presented at the European and Mediterranean Conference on Information Systems, Dubai, May 25-26, 2008).

39. H. Akkermans and K. van Helden, "Vicious and Virtuous Cycles in ERP Implementation: A Case Study of Interrelations between Critical Success Factors," European Journal of Information Systems 11, no. 1 (2002): 35-46, http://dx.doi.org/10.1057/palgrave.ejis.3000418.

40. Nancy Bancroft, Henning Seip, and Andrea Sprengel, Implementing SAP R/3: How to Introduce a Large System Into a Large Organisation (Greenwich, UK: Manning, 1998).

41. Nah, "Critical Success Factors." 
42. Toni M. Somers and Klara Nelson, "The Impact of Critical Success Factors Across the Stages of Enterprise Resource Planning Implementations," Proceedings of the 34th Hawaii International Conference on System Sciences, 2001, http://dx.doi.org/10.1109/HICSS.2001.927129.

43. Shi-Ming Huang et al., "Assessing Risk in ERP Projects: Identify and Prioritize the Factors," Industrial Management \& Data Systems 104, no. 8 (2004): 681-88, http://dx.doi.org/10.1108/02635570410561672.

44. Nah, "ERP Implementation."

45. Umble, “Enterprise Resources Planning.”

46. Nah, "ERP Implementation."

47. “Basecamp, in a Nutshell,” Basecamp, https://basecamp.com/about/press.

48. Nah, “ERP Implementation.”

49. Umble, "Enterprise Resources Planning."

50. Mo Adam Mahmood et al., "Variables Affecting Information Technology End-user Satisfaction: A Meta-analysis of the Empirical Literature," International Journal of Human-Computer Studies 52, no. 4 (2000): 751-71, http://dx.doi.org/10.1006/ijhc.1999.0353.

51. Iuliana Dorobat and Floarea Nastase, “Training Issues in ERP Implementations," Accounting \& Management Information Systems 11, no. 4 (2012): 621-36.

52. Anne Beaudry and Alain Pinsonneault, "The Other Side of Acceptance: Studying the Direct and Indirect Effects of Emotions on Information Technology Use," MIS Quarterly 34, no. 4 (2010): 689-710.

53. Shaul and Tauber, "Critical Success Factors in Enterprise Resource Planning Systems.”

54. Andrew Lawrence Norton et al., "Ensuring Benefits Realisation from ERP II: The CSF Phasing Model," Journal of Enterprise Information Management 26, no. 3 (2013): 218-34, http://dx.doi.org/10.1108/17410391311325207.

55. Chong Hwa Chee, "Human Factor for Successful ERP2 Implementation," New Straits Times, July 28, 2003, https://www.highbeam.com/doc/1P1-76161040.html. 